La tuberculosis: principal asesina de mujeres jóvenes

La tuberculosis (TB) se ha convertido en la enfermedad infecciosa más peligrosa del mundo para las mujeres jóvenes. La OMS presentó datos que corroboran esa aseveración en una reunión internacional de investigadores sobre la TB y su distribución epidemiológica por géneros, que se celebró en Gotenburgo, Suecia, del 24 al 26 de mayo de 1998. Se informó de niveles extraordinarios de infección y muerte en mujeres y niñas, con más de 900 millones infectadas actualmente por el bacilo en todas partes del mundo. Durante el año en curso es de esperar que un millón de mujeres entre los 15 y los 44 años de edad mueran por esa causa y que 2,5 millones adquieran la enfermedad. Mientras que la guerra es responsable de $4 \%$ del total mundial de muertes en mujeres de esa edad, el VIH de 3\% y la enfermedad cardíaca de otro 3\%, la TB da cuenta de $9 \%$ de esas muertes. Una vez contraída la infección, las mujeres en edad reproductiva son más susceptibles que los hombres de enfermar gravemente. Además, están en mayor riesgo que los hombres de infección por VIH. Las grandes pérdidas humanas ocasionadas por esta enfermedad han impulsado la búsqueda de factores, tales como el sexo, que ayuden a comprender y contener la epidemia. Sin embargo, de las enfermedades que amenazan la salud de las mujeres, la TB es quizá la más económica de controlar. La reunión realizada en Suecia es el primer acontecimiento internacional sobre el tema de la TB y el género, y en ella los expertos de ambos campos planearon una agenda de investigación sobre las diferencias biológicas, epidemiológicas, sociales y culturales que puedan influir en la aparición más frecuente de la TB en mujeres y en el acceso de ellas a la estrategia de tratamiento bajo observación directa (TOD) que promueve la OMS. Los participantes acordaron investigar concretamente los temas del embarazo y la $\mathrm{TB}$, el diagnóstico de $\mathrm{TB}$ en la mujer, la observancia del tratamiento y la educación de las pacientes. También se recomendó facilitar el acceso al TOD mediante servicios extrainstitucionales, horas de visita flexibles en las clínicas y adiestramiento de los agentes de salud para que sepan responder a las necesidades de la mujer en particular. Esta estrategia de tratamiento combina cinco elementos: compromiso político, detección de la TB por microscopia de frotis de esputo, tratamiento breve bajo observación directa, administración regular de los fármacos y sistemas de monitoreo para evaluar el resultado del tratamiento en cada una de las pacientes. Después de que los casos infecciosos de TB se detectan por microscopia, el personal de salud y los agentes y voluntarios comunitarios supervisan la toma de dosis apropiadas de medicamentos por las pacientes, llevan los registros correspondientes y certifican la curación cuando es debido. (Organización Mundial de la Salud. TB is single biggest killer of young women. Comunicado de prensa $\mathrm{WHO} / 40,26$ de mayo de 1998.)

\section{Deben revisarse las indicaciones sobre vitamina D}

Además de prevenir la osteoporosis y las fracturas óseas en la gente mayor, la vitamina $\mathrm{D}$ es la precursora esencial de la 1,25-dihidrovitamina D, hormona esteroide que hace falta para el crecimiento de los huesos en los niños y la conservación de hueso en los adultos. Si bien el raquitismo y la osteomalacia - consecuencias de la carencia grave de vitamina D- ya casi han desaparecido, cada día se hace más evidente que la deficiencia de esa vitamina es un factor de riesgo común en la fractura y pérdida de hueso en personas mayores o enfermas. Un estudio llevado a cabo en 290 pacientes (con una media de edad de 62 años) admitidos consecutivamente a los servicios médicos generales de un hospital de Massachusetts, Estados Unidos de América, indicó que la hipovitaminosis $\mathrm{D}$ era común aun entre quienes ingerían más de las 200 UI diarias de vitamina D recomendadas para los adultos. Recientemente, el Consejo de Alimentación y Nutrición del Instituto de Medicina estableció una nueva "ingesta adecuada", que aumenta a 400 UI diarias la que debe tomar el grupo de 51 a 70 años y a 600 UI la de personas mayores de esa edad.

La vitamina $D$ es esencial para absorber el calcio y mantener la integridad de la estructura ósea. Al natural, la vitamina D se obtiene de la luz solar y de los alimentos. En la piel, la radiación ultravioleta estimula la conversión de 7-dehidrocolesterol a previtamina $\mathrm{D}$, que se convierte espontáneamente en vitamina D. La cantidad de vitamina así obte- 
nida es difícil de medir y sus efectos se reducen con la edad, la pigmentación de la piel, el uso de protectores contra el sol, la ropa y hasta el tipo de vidrio que cubre las ventanas. Algunos alimentos como los productos lácteos, los huevos y el pescado contienen un poco de vitamina $\mathrm{D}$, pero los alimentos enriquecidos (como la leche, las fórmulas infantiles y los cereales, en los EUA) contienen mucha más. Cualquiera que sea su origen, la vitamina $\mathrm{D}$ se convierte secuencialmente en 25-hidroxivitamina $\mathrm{D}$ en el hígado y en 1,25-dihidroxivitamina D (la hormona activa) en los riñones. La medición de la 25hidroxivitamina D en el suero es la que proporciona más información porque tiene una semivida de semanas, mientras que la vitamina D dura solo horas. Se ha observado que la concentración de 25-hidroxivitamina $\mathrm{D}$ disminuye con la edad y aumenta levemente con la exposición al sol y la ingestión de vitamina D. En el estudio mencionado, $164(57 \%)$ de los 290 pacientes tenían deficiencia de vitamina D. Las concentraciones de esta vitamina tuvieron una relación inversa con las de hormona paratiroidea y la hipovitaminosis se relacionó de forma significativa con menor exposición a luz ultravioleta, terapia anticonvulsiva, diálisis renal, síndrome nefrótico, hipertensión, diabetes mellitus, meses de invierno, concentraciones más altas de hormona paratiroidea y fosfatasa alcalina, y concentraciones más bajas de calcio ionizado y albúmina. Otros factores que intervienen en la hipovitaminosis D son las enfermedades crónicas de hígado y riñones, y la terapia con medicamentos que perjudican la activación de la vitamina o que aceleran su aclaramiento, como la fenitoína, carbamazepina y rifampicina. En general, las enfermedades son un factor que agrava la carencia de vitamina D.

La hipovitaminosis D dista de ser solamente una anormalidad bioquímica. Está asociada con pruebas fisiológicas, patológicas y clínicas como el aumento de secreción de hormona paratiroidea y resorción ósea, osteoporosis y osteomalacia leve, y mayor riesgo de fracturas. Deben tomarse medidas para aumentar la ingesta de vitamina $\mathrm{D}$ en todos los adultos y su concentración en los alimentos enriquecidos y en combinaciones de vitaminas múltiples. Según los conocimientos actuales, la gente mayor y los enfermos - y hasta posiblemente todos los adultos- necesitan de 800 a 1000 UI diarias de vitamina D. Esto deja un amplio margen de seguridad, pues la hipercalciuria y la hipercalcemia no suelen aparecer hasta que la dosis diaria llega a un mínimo de 2400 UI. (Thomas MK, Lloyd-Jones DM, Thadhani RI, Shaw AC, Deraska DJ, Kitch BT, et al. Hypovitaminosis D in medical inpatients. $N$ Engl J Med 1998;338:777-783 y Utiger RD. The need for more vitamin D [editorial]. N Engl J Med 1998; 338:828-829.)

\section{Inestabilidad mutacional en la mitosis de células cancerosas}

Hace ya 20 años que los investigadores del cáncer hacen frente a la paradoja de que la aparición de tumores y su proliferación en el ser humano requieren tantos genes mutágenos que su acumulación en el genoma sería matemáticamente imposible durante una sola vida. Sin embargo, nuevos experimentos por D. P. Cahill et al. proporcionan una especie de mapa para resolver la paradoja. Muestran que, en las células de cáncer colorrectal, los mecanismos que controlan la separación de los cromosomas durante la división celular pueden estar defectuosos. Lawrence Loeb, el autor que postuló la improbabilidad de que pudiera completarse la progresión de un tumor humano, repasó sus cifras y concluyó que uno de los parámetros fundamentales de sus cálculos iniciales —el ritmo de mutación- había sido subestimado y que la tumorigénesis puede ocurrir solamente si los genomas de las células premalignas son más mutables que los de las células normales. De existir esta cualidad se aceleraría mucho el proceso. Estos tipos de cálculo dan lugar a buenas conjeturas, pero dejan todavía demasiados parámetros críticos sin medir. No obstante, ha habido observaciones directas de la inestabilidad genética de las células tumorales. En una pequeña fracción de cánceres colorrectales, la reparación defectuosa de bases desiguales aumenta la mutación en los nucleótidos y produce errores de replicación. Sin embargo, en la mayor parte de esos cánceres se observa una inestabilidad genética que produce un número anormal de cromosomas (aneuploidia) y pérdida de la heterocigosidad en muchos loci. No se conocen las causas fisiológicas ni moleculares de esa anormalidad, pero ello sugiere que la generación de aneuploidia es un mecanismo mutágeno alternativo al de la reparación de bases desiguales para impulsar la progresión de los tumores.

La aneuploidia puede resultar de la distribución inapropiada de las dos cromátides de un cromosoma a las células de la descendencia durante la mitosis. Normalmente, hay un punto de control que regula la ensambladura correcta del huso cromático y tira de las cromátides para separarlas. Si los cromosomas no están adheridos establemente a los microtúbulos que forman el huso, en el punto de control se bloquea la anafase. Este defecto de la ensambladura produce aneuploidia. Muchas de las líneas de células colorrectales tumorales tienen inestabilidad cromosómica continua in vitro. Los estudios de Cahill et al. muestran que esa inestabilidad deriva de un defecto en el punto de control de la ensambladura del huso. Además, en algunas células cancerosas con esas características, la fun- 
ción defectuosa del punto de control se asoció con la desactivación mutacional de un homólogo humano del gen de levadura BUB1, el cual rige los puntos de control mitóticos y la segregación de cromosomas en las levaduras. Los puntos de control de mitosis normal de células que muestran errores de replicación se han vuelto defectuosos al recibir alelos mutantes hBUB1 de cánceres con inestabilidad cromosómica. Con el trabajo de Cahill et al. comienza a comprobarse que la aneuploidia adquirida es una fuerza motora de la progresión de los tumores $\mathrm{y}$, posiblemente, que la mutabilidad es una característica general de los genomas de células tumorales. (Cahill DP, Lengauer C, Yu J, Riggins GJ, Willson JK, Markowitz SD, et al. Mutations of mitotic checkpoint genes in human cancers. Nature 1998;392:300-303 y Orr-Weaver TL, Weinberg RA. A checkpoint on the road to cancer. Nature 1998; 392:a223-224.)

\section{¿Son mejores las médicas que los médicos en obstetricia y ginecología?}

Para tratar de dar respuesta a esta pregunta, se estudió el desempeño de 128 estudiantes de medicina osteopática de ambos sexos después de un módulo de aprendizaje de 4 semanas en su segundo año escolar. El curso, dedicado básicamente a la reproducción humana, comprendía elementos clínicos de obstetricia y ginecología y fue seguido de un examen de 80 preguntas. En el tercer año, los estudiantes hicieron rotación en una pasantía clínica que incluyó 2 semanas de obstetricia, una semana de cirugía ginecológica y 3 semanas de atención obstétrica y ginecológica ambulatoria. Inmediatamente después de la rotación, los estudiantes fueron evaluados por médicos supervisores en muchos aspectos de su trabajo, incluidas las relaciones con las pacientes, y recibieron calificaciones en un formulario de evaluación clínica. El estudio que nos ocupa se basó en la calificación general de la pasantía y de las relaciones con las pacientes. En esta última materia, recibieron la calificación de "superior" aquellos estudiantes que mostraron comprensión y solicitud hacia sus pacientes y que formaron vínculos con ellas. Se calificaron "promedio" si las pacientes se sentían razonablemente a gusto con ellos; e "inaceptables" si las pacientes se quejaban del estudiante o si el supervisor opinaba que la interacción con las pacientes dejaba que desear. La calificación general comprendía las habilidades relacionadas con conocimientos, historia, examen físico, perspicacia para diagnosticar, llevar registros, actitud y prefesionalismo, forma de relacionarse con las pacientes, actividades educativas, presentaciones clínicas y lecturas extracurriculares. Para efectos del estudio, se agrupó a los estudiantes en dos categorías: aprobados con nota baja o aprobados, y aprobados con nota alta o con honores.

Se evaluó un total de 127 estudiantes, $70(55 \%)$ de ellos hombres y 57 (45\%), mujeres. Se excluyó a un estudiante varón que no pasó el examen del módulo y no entró en la pasantía. En el examen, los estudiantes varones tuvieron una nota promedio de 46,56 (DE 9,78) y las mujeres, de 49,14 (DE 9,19). En la pasantía de tercer año, recibieron nota alta o con honores sobre relaciones con las pacientes 50 hombres $(71,4 \%)$ y 48 mujeres $(84,2 \%)$. Las notas bajas correspondieron a 28 hombres $(28,6 \%)$ y nueve mujeres $(15,8 \%)$. Esas diferencias no fueron estadísticamente significativas. Sin embargo, para la pasantía en general solo 20 hombres (40\%) recibieron calificaciones altas o de honor, mientras que 38 mujeres $(66,7 \%)$ las tuvieron; 42 hombres $(60 \%)$ y 19 mujeres $(33,3 \%)$ recibieron notas bajas. Estas diferencias fueron muy significativas $(P=0,0028)$.

Fue evidente que, en el caso estudiado, las estudiantes sobrepasaron con mucho a los varones durante la pasantía en obstetricia y ginecología. Las razones para ello no han quedado claras. Sin embargo, fue sorprendente que no hubiera diferencias entre hombres y mujeres en cuanto a la relación con las pacientes, ya que es de pensar que su experiencia personal como pacientes de ginecología y obstetricia llevaría a las médicas a relacionarse mejor con las pacientes. Menos sorprendente fue que no hubiera diferencias en las notas del examen sobre el módulo de segundo año, ya que todos los estudiantes admitidos a la escuela tenían notas similares al entrar. Se podría pensar en un sesgo al calificar la pasantía, ya que los formularios de evaluación son menos objetivos que los exámenes. No obstante, hay poca probabilidad de que el sesgo apareciera en la calificación general y no en la de las relaciones con las pacientes. El asunto merece investigación ulterior. (Krueger PM. Do women medical students outperform men in obstetrics and gynecology? Acad Med 1998;73:101-102.)

\section{Factibilidad de una vacuna comestible}

Como apertura a una nueva era en la inmunización, investigadores apoyados por el Instituto Nacional de Alergias y Enfermedades Infecciosas de los Estados Unidos de América acaban de demostrar que pueden provocarse respuestas inmunitarias inocuas en las personas mediante una vacuna comestible. El informe sobre el ensayo en seres humanos en el cual colaboraron la Universidad de Maryland en Baltimore, Maryland; el Instituto Boyce Thompson de Investigación sobre las Plantas en Ithaca, Nueva York; y la Universidad Tulane en 
Nueva Orleans, Luisiana, se ha publicado en el número de mayo de 1998 de la revista Nature.

El ensayo de la fase 1 (verificación del concepto) comenzó en el Centro de Desarrollo de Vacunas de la Escuela de Medicina de la Universidad de Maryland. Los participantes voluntarios comieron porciones de papa cruda transgénica que había sido sometida a ingeniería genética para producir parte de la toxina segregada por Escherichia coli, bacteria que causa diarrea. Previamente se había establecido que las papas transgénicas que contenían ese segmento de la toxina estimulaban una fuerte respuesta inmunitaria en animales. Las papas fueron cultivadas en el Instituto Boyce Thompson, afiliado de la Universidad de Cornell.

En el ensayo participaron 14 adultos sanos, de los cuales 11 fueron escogidos al azar para recibir las papas transgénicas y tres recibieron porciones de papas corrientes. Las papas se pelaron antes de ingerirse para evadir el sabor amargo que a veces tiene la cáscara y evitar problemas de náusea o vómito en los sujetos de estudio. Luego se cortaron en pedacitos uniformes de 50 y $100 \mathrm{~g}$, con objeto de probar dos dosis diferentes y averiguar si había efectos secundarios debido a la cantidad de papa cruda ingerida. Cada participante recibió tres dosis de 50 o $100 \mathrm{~g}$ a lo largo de 3 semanas, en los días 7 y 21. Se recogieron periódicamente muestras de sangre y heces de los voluntarios para evaluar la capacidad de la vacuna de producir respuestas inmunitarias tanto sistémicas como intestinales.

En 10 de los 11 (91\%) que comieron las vacunas de papa aumentó cuatro veces el número de anticuerpos en algún momento después de la inmunización y en seis de los 11 (55\%) hubo aumentos de esa misma magnitud en anticuerpos intestinales. Nadie experimentó efectos adversos por haber comido las papas, que fueron bien toleradas. Alentados por estos resultados, los científicos están explorando el uso de la misma técnica para administrar otros antígenos. Ya hay varias vacunas comestibles en elaboración, entre ellas algunas papas y plátanos que protegen contra el virus Norwalk, causa común de diarrea, y papas y tomates eficaces contra la hepatitis B. Se vislumbra que las vacunas comestibles puedan cultivarse en muchos de los países en desarrollo donde se usarían. Las vacunas comestibles ofrecen nuevas posibilidades de reducir notablemente la carga de enfermedades como las hepatitis y las diarreas, sobre todo en el mundo en desarrollo, donde el almacenaje y la administración de vacunas pueden presentar grandes problemas. (U.S. National Institutes of Health, National Institute of Allergy and Infectious Diseases. First human trial shows that an edible vaccine is feasible. Comunicado de prensa, 27 de abril de 1998.)

\section{¿Afecta el amamantamiento a la capacidad de respuesta inmunitaria del lactante?}

En Acta Paediatrica se ponderan los resultados de una investigación divulgada meses antes en la misma revista, en la cual los autores, Pabst et al., concluyen que en los niños lactados con leche materna hay un efecto inmunomodulador de largo plazo que no se produce en los alimentados con biberón. La investigación comprende dos estudios relacionados, de lactantes de 6 y 12 meses de edad, respectivamente, de los cuales cerca de la mitad fueron amamantados (grupo A) y la otra mitad, alimentados con fórmula en biberón (grupo B). La medición de base de integrinas en los linfocitos CD4+, CD8+ y CD19+ fue significativamente menor en los niños amamantados, lo cual parece indicar mayor activación de los linfocitos circulantes en los niños B. Tras estimulación de los linfocitos sanguíneos con toxoide tetánico o antígeno Candida, se midió la respuesta proliferativa y de producción de interferón gamma, que de nuevo fue menor en los niños $\mathrm{A}$. También se midieron la transformación de blastos y producción de citoquinas por linfocitos, y los cambios en las células T antes y después de vacunar a los niños con virus vivos atenuados de sarampiónparotiditis-rubéola. Antes de la vacuna, los linfocitos de los niños A tenían concentraciones más bajas de transformación de blastos y menor producción de interferón-gamma que los B. Sin embargo, al decimocuarto día después de la vacunación, la producción de interferón-gamma y los porcentajes de células CD56+ y CD8+ aumentaron solo en los niños A.

Los comentaristas Wold y Adlerberth, de la Universidad Göteborg de Suecia, explican que la mayor activación de linfocitos en los niños B podría deberse a su exposición a proteínas alimentarias extrañas, si bien no es probable que los antígenos alimentarios por sí mismos den lugar a una activación linfocítica notable. También debe considerarse que la presencia de factores antiinflamatorios y antiproliferativos en la leche materna podrían haber reducido la activación del sistema inmunitario y, segundo, que los niños B tuvieran una microflora intestinal más variada y capaz de estimular ese sistema. La leche materna contiene muchos factores que podrían modularlo, incluidas las citoquinas inflamatorias (IL-1, TNF- $\alpha$ ) y antiinflamatorias (TGF- $\beta$, IL-10), la prostaglandina $\mathrm{E}_{2}$, grandes números de macrófagos y de linfocitos T CD8+ activados, la lactoferrina, los oligosacáridos y el factor de crecimiento epidérmico.

La lactación afecta la microflora, que tiene más estafilococos en los niños A que en los B, pero menos enterococos, clostridios, Bacteroides y enterobacterias. Por otra parte, es posible que la flora intestinal de los lactantes al pecho sea menos variada y provoque una menor estimulación inmunitaria. 
En los A hay menos cepas de Escherichia coli y altas concentraciones de IgA, la cual inhibe la translocación de bacterias. Esta puede ser una razón importante de la protección contra la sepsis que se observa en los niños amamantados. Estas diferencias entre niños alimentados al pecho y con biberón suelen desaparecer una vez destetados, pero en los países superhigiénicos del primer mundo, la exposición a bacterias ambientales es muy baja y puede retrasar el desarrollo de flora intestinal de tipo adulto. El artículo comentado sugiere que los niños A tienen una respuesta más activa que los $\mathrm{B}$ a antígenos específicos, como en la inmunización. Wold y Adlerberth informan de diversos estudios en los que no se ha observado ninguna diferencia entre los A y B en cuanto a la respuesta de anticuerpos a las vacunas contra tétanos, difteria, poliovirus, pertusis o influenza. A menudo la respuesta a vacunas absorbidas por las mucosas es menor en los niños A. Esto se atribuye a la inhibición de la replicación de virus en el intestino o a su salida más rápida de las superficies mucosas debido a la secreción de anticuerpos IgA y otros factores de la leche materna.

La respuesta inmunitaria mediada por células en niños A y B ha sido poco estudiada. Si bien Pabst et al. anteriormente habían demostrado mayor proliferación de células $\mathrm{T}$ en un grupo A que en uno B, ambos vacunados con BCG al nacer, en el estudio que aquí se cita la respuesta proliferativa de linfocitos a la hemaglutinina del sarampión fue algo más baja en el grupo A. Los autores proponen que la lactancia natural promueve una respuesta de tipo Th1. Las Th1 son células T CD4-+, que segregan citoquinas IL-2 e IFN- $\gamma$ y promueven reacciones tardías de hipersensibilidad (como la reacción a la tuberculina). Las Th2 segregan IL-4, IL-5 e IL-10 y ayudan a las células $\mathrm{B}$ a madurar y convertirse en productoras de anticuerpos. Si fuera cierto que la lactancia materna promueve una respuesta Th1 y suprime la Th2, podría prevenir las alergias, pero no hay pruebas de esos efectos en el sistema inmunitario. Más lógico parecería pensar que los niños $\mathrm{A}$, al no consumir leche de vaca, tampoco consumen ciertos alérgenos potenciales. Actualmente, en Suecia están aumentando tanto las alergias como la lactancia materna. Aparte de su función nutritiva, la leche materna probablemente ha evolucionado para asegurar la supervivencia infantil en ambientes muy contaminados. Sería demasiado esperar, opinan Wold y Adlerberth, que nos protegiera también de ambientes demasiado limpios. (Wold AE, Adlerberth I. Does breastfeeding affect the infant's immune responsiveness? Acta Paediatr 1998;87:19-22; Pabst HF, Spady DW, Pilarsky LM, Carson MM, Beeler JA, Krezolek MP. Differential modulation of the immune response by breast- or formula-feeding infants. Acta Paediatr 1997;86:1291-1297.)

\section{Regeneración de músculos atrofiados mediante trasplantes de médula ósea}

Un equipo de investigadores italianos ha ofrecido pruebas preliminares de que algún día se podrán regenerar los músculos atrofiados con células nuevas de una fuente inesperada: la médula ósea del propio paciente. Hasta ahora, los experimentos se han realizado solamente en ratones, pero abren toda clase de posibilidades terapéuticas mediante la introducción de células de la médula ósea en músculos degenerados por distrofias, para convertirlas en nuevas células musculares.

Los resultados obtenidos por biólogos de Milán y Roma contradicen el dogma de que los músculos forzosamente dependen de células locales para reparar las lesiones. La idea surgió hace 2 años, cuando casi todos los investigadores pensaban que las llamadas células satélites que rodean a las fibras musculoesqueléticas eran las únicas capaces de desempeñar regularmente la función de sanarlas. Sin embargo, el hecho de que pueden crecer en una zona lesionada muchas más células nuevas que las satélites allí presentes hacía sospechar que hubiera otras células involucradas, si bien nadie había podido descifrar cuáles eran. El grupo italiano obtuvo resultados sorprendentes mientras experimentaba en ratones para averiguar si los fibroblastos, además de formar tejido conectivo, podían formar músculo. Como controles, inyectaron otros tipos de células, incluidas las de médula ósea exentas de fibroblastos. Luego indujeron lesiones musculares en todos los ratones con la esperanza de que acaso se formaran células premusculares nuevas en los ratones que recibieron los fibroblastos. En cambio, los mejores resultados se vieron en los que recibieron médula ósea sin fibroblastos. En realidad, dos equipos de investigadores estadounidenses habían anteriormente demostrado in vitro que podía inducirse a las células del estroma medular a convertirse en precursoras de células musculares. Para averiguar si lo mismo podía ocurrir en animales, los científicos italianos recibieron ayuda de colegas en el Instituto Pasteur, de París, en la forma de una nueva línea de ratones transgénicos portadores de un gen marcador que hace, al activarse, que los núcleos de las células se tornen azules. Puesto que esto ocurre solo en las células de los músculos, sirve para distinguir las células de médula que hayan migrado a un músculos lesionado para convertirse en células musculares nuevas. En los experimentos realizados en Italia, se transplantó médula con gen marcador a ratones cuya médula había sido destruida por radiación. Después de varias semanas, se inyectó a los ratones una toxina que les lesionó los músculos de las patas. Dos semanas más tarde se comprobó que en nueve 
ratones las zonas lesionadas no solo mostraban signos de recuperación sino que tenían numerosos núcleos azules: los núcleos de células medulares que se transformaron en músculo. Se ha planteado el posible problema de que en los ratones transgénicos haya células satélites funcionales, lo cual no sucede en seres humanos con distrofia muscular. Es decir, no se sabe si la regeneración puede ocurrir sin esas células. Actualmente, el equipo italiano está repitiendo el transplante de médula ósea, pero en ratones que tienen el mismo defecto genético que las personas con distrofia muscular de Duchenne. Sería un gran adelanto si en estos ratones se lograra la transformación de células de la médula en células musculares. En último término, un paciente podría donar una pequeña cantidad de médula a la cual se añadirían copias normales del gen de la distrofia muscular. Una vez que las células se multiplicaran, se inyectarían de nuevo en los pacientes para formar músculo nuevo y sano. Pero eso todavía no está a la vuelta de la esquina. (Ferrari G, Cusella-De AG, Coletta M, Paolucci E, Stornaiuolo A, Cossu G, et al. Muscle regeneration by bone marrow-derived myogenic progenitors. Science 1998;279:1528-1530 y Pennisi E. Bone marrow cells may provide muscle power. Science 1998;279:1456.)

\section{Oficina Internacional de Epizootias inaugura representación en las Américas}

El 11 de febrero de 1998 se inauguró en Buenos Aires, Argentina, una representación regional de la Oficina Internacional de Epizootias (OIE), organización mundial de sanidad animal creada en 1924 con sede en París. La OIE incluye a 149 países cuyos delegados componen el Comité Internacional, que se basa en los trabajos de sus comisiones especializadas y regionales. Su misión consiste en informar y asesorar a los servicios veterinarios de los países miembros, para contribuir a erradicar las zoonosis más peligrosas para los animales y los seres humanos y establecer las normas sanitarias que deben aplicarse en los intercambios internacionales de animales y productos de origen animal.

El principal objetivo de la representación regional, cuya dirección se puso en manos del profesor Emilio Gimeno, será contribuir a la vigilancia de las enfermedades de animales en la Región, armonizar su control y capacitar a técnicos veterinarios nacionales en el análisis de los riesgos zoosanitarios. El programa de los tres años próximos se estableció de común acuerdo con los países miembros de la OIE en las Américas. Uno de los objetivos más importantes será intensificar la lucha contra la fiebre aftosa, de la cual la OIE ya ha declarado oficialmente libres a varios países de las Américas. 